\title{
An investigation into the dynamics of lip-prints as a means of identification
}

\author{
Anika Ludwig ${ }^{1 *}$ and Helen Page ${ }^{2}$ \\ ${ }^{1}$ Centre for Forensic Science, School of Life Sciences, Northumbria University, Ellison Building, \\ Newcastle-upon-Tyne, NE1 8ST, UK \\ ${ }^{2}$ Centre for Forensic Investigation, School of Science \& Technology, University of Teesside, \\ Middlesbrough, TS1 3BE, UK \\ *Corresponding author
}

Telephone: (+44) (0191) (243-7643)

Email: anika.ludwig@northumbria.ac.uk 


\section{$\underline{\text { Abstract }}$}

Individualisation and identification by analysing the lines and furrows contained within the lip patterns has been broadly discussed in the literature; however, due to a lack of research their reliability as evidence is questioned. Research was undertaken to test the classification system of lip print patterns and features which had previously been established and aimed to determine a method for cataloguing lip prints to include lip pattern typing and the comparison of pattern imperfections.

Two sets of lip prints (eight impressions in total) were collected from 36 volunteers (25 females, 11 males). Volunteers were recruited at Teesside University and the University of Edinburgh. The ages of volunteers ranged from 21-60 years and all were considered of Caucasian race.

The research found that lip patterns could be divided into five types, each type increasing in furrow complexity. Characteristic details from the lip prints were annotated based on the classification terminology used in fingerprint analysis (e.g. bifurcation) as well as classification systems used by other researchers previously. Lip print impressions were compared to known and unknown individuals as well as photographs, and the results demonstrated that it was possible to establish whether an impression could be linked to the correct source.

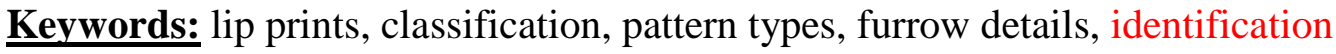




\section{$\underline{\text { Introduction }}$}

Accurately identifying individuals (both deceased and living) is not only important in the forensic field but also in everyday life. However, current methods used to identify individuals predominantly focus on fingerprint and DNA analysis. A less common procedure is the analysis of lip prints (or cheiloscopy), described as a complex system of lines, furrows and

fissures forming wrinkles and grooves on the skin of the red area of human lips ${ }^{1-4}$. Utsuno et $a l .{ }^{5}$ recognised that, in forensic identification, the lips and mouth allow for the analysis of numerous distinctive characteristics including the number and condition of teeth as well as features such as lip pigmentation, texture, lip size and mouth shape. In general, lips thickness has been classified into four main groups: thin lips - common in European Caucasian individuals; medium lips - most common type (between 8-10mm); thick lips - common in African American race; and mixed lips - common in the Oriental population ${ }^{6}$.

Lip shape can be described as depressed, elevated or horizontal ${ }^{7}$. It has become recognised that lips thin due to aging, resulting in less defined features. Youthful lips are therefore considered to be those that appear rounded and full in appearance, where consequent plastic surgery procedures have developed techniques to mimic and create fuller, larger lips ${ }^{8,9}$. Variations between lip prints occur due to differences in the number and position of furrows, their relative relation to other furrows and general differences in length, thickness and complexity of branching which produce a distinctive combination of grooves and pattern details $^{10-13}$. Tsuchihashi ${ }^{14}$ observed that lip prints, like fingerprints, remain unchanged in a person life and are unlikely to be modified once they are formed.

The muscles of the lips can swell temporarily, become inflamed and tender due to injury, medical side effects, sexual stimulation or misalignment of the teeth ${ }^{15}$. Lips become chapped and split much more easily compared to other skin types because of their nature and require regular treatment. Lip wrinkles occur due to the failure (or inability) of skin to recover from distortion or deformation caused by recurrent activities like eating, smiling, speaking, etc. Lévêque and Goubanova ${ }^{16}$ observed the strong interaction of lips within the orbicularis muscle causes continual deformation of the mobile tissue as where the noticeable wrinkles remained unchanged through time. The high prevalence of wrinkles and the fact that they are easily observable means that these furrows are potentially of interest for forensic identification. 
Standard systematic procedures for cheiloscopic examinations involve identifying corresponding characteristics and contours through the use of photographic montage (overlay) from lip print traces. Kasprzak ${ }^{17}$ identified that prints displaying clearly visible furrows and individual elements resemble identification features similarly used in dactyloscopic (friction ridge skin/fingerprint) traces where similar theories of recombination is applied. Two features of similar shape and size may appear in the same location by chance but the likelihood of several such features sharing the same location and physical appearance between two participants is unlikely. Thus, the more features analysed, the more individualistic the combination of the individual features becomes.

This study was designed to determine whether sufficient details are available from lip print impressions and subsequent photographs to allow an individual to be identified and whether impressions and lips can be linked to each other. To achieve this; lip prints were analysed to determine the presence or absence of significantly distinctive details which may allow for the positive identification of an individual ${ }^{14,18}$.

\section{Materials and Method}

\section{Sampling}

Volunteers were recruited from Teesside University and the University of Edinburgh in the UK. An information sheet and a consent form were given to each volunteer detailing the aims and methods of the project. A total of 36 volunteers were included in this study, 25 females and 11 males. The age of the volunteers ranged from 21 to 56 years of age, and the average mean age was 29 years. Only lips which were free from disease and inflammation (e.g. cold sores, chapping) were included. Lips which displayed deformities, obvious scarring and other lip abnormalities were excluded from the study.

\section{Method for collection}

A dark coloured non-glossy, non-persistent lipstick (Natural Collection ${ }^{\circledR}$ Hazelnut Moisture Shine Lipstick) was used to get clear prints ${ }^{5,19,20}$. Permanent lipsticks were not found suitable in such studies as they did not produce clear impressions when in contact with a substrate ${ }^{19}$. Epson ${ }^{\circledR}$ white 80 mgs office copy paper was used to the record impressions as it produced the greatest contrast with the darker coloured lip stick ${ }^{21}$. Other substrates (card, plastic, 
acetate, etc.) were tested, but were found to produce less clear impressions. Participants pressed their 'painted' lips against a folded piece of paper, producing highly detailed prints of a neutral (relaxed) expression. A second method was utilised which required participants to hold the piece of paper against a rolling pin and gently roll this across their slightly parted lips. The prints were carefully sealed with standard fingerprint adhesive tape, photographed and scanned for further analysis and comparison.

To ensure relative uniformity of the impressions, clear step-by-step instructions of how to take standardised lip print impressions were devised and given to the volunteers. These were strictly adhered to, as the mobility of lips and the direction of pressure exerted by the participants affects the accurate replication of lip prints, altering the subsequent impression ${ }^{22}$. A series or multiple versions of impressions (of varying shades) were taken of the same print to ensure all parts of the lips were accurately recorded and the details did not significantly vary. The following points were carefully considered and controlled to the researchers' best ability to obtain repeatable lip print impressions: the mouth was cleaned - any debris debris, blood, fluid etc, removed to ensure a clear print was recorded, the lips were sufficiently dry to ensure printing medium adheres accurately to the details, and the printing medium was applied in a thin, even layer - too much may obscure the groove patterns and result in an inaccurate impression.

\section{Classification system}

Previous studies have identified a number of different classification systems; from simple and compound groups containing vertical, branched, bifurcated, intersected, reticular, horizontal and irregular patterns ${ }^{18,23}$. Lip prints were organised into five types according to the details and can be seen in figure 1. These included: TYPE I: vertical t, TYPE II: branched, TYPE III: intersecting, TYPE IV: reticular, and TYPE V: undetermined or mixed patterns. The upper and lower lips were split into six sections as illustrated by figure 2, and classified into a specific type. Each lip was divided into three sections: upper - left, middle and right (UL, UM, UR), and lower - left, middle and right (LL, LM, LR). The upper and lower middle sections were used to determine the lip print pattern overall as these sections exhibit the greatest lip surface area, therefore containing the majority of furrow details. 


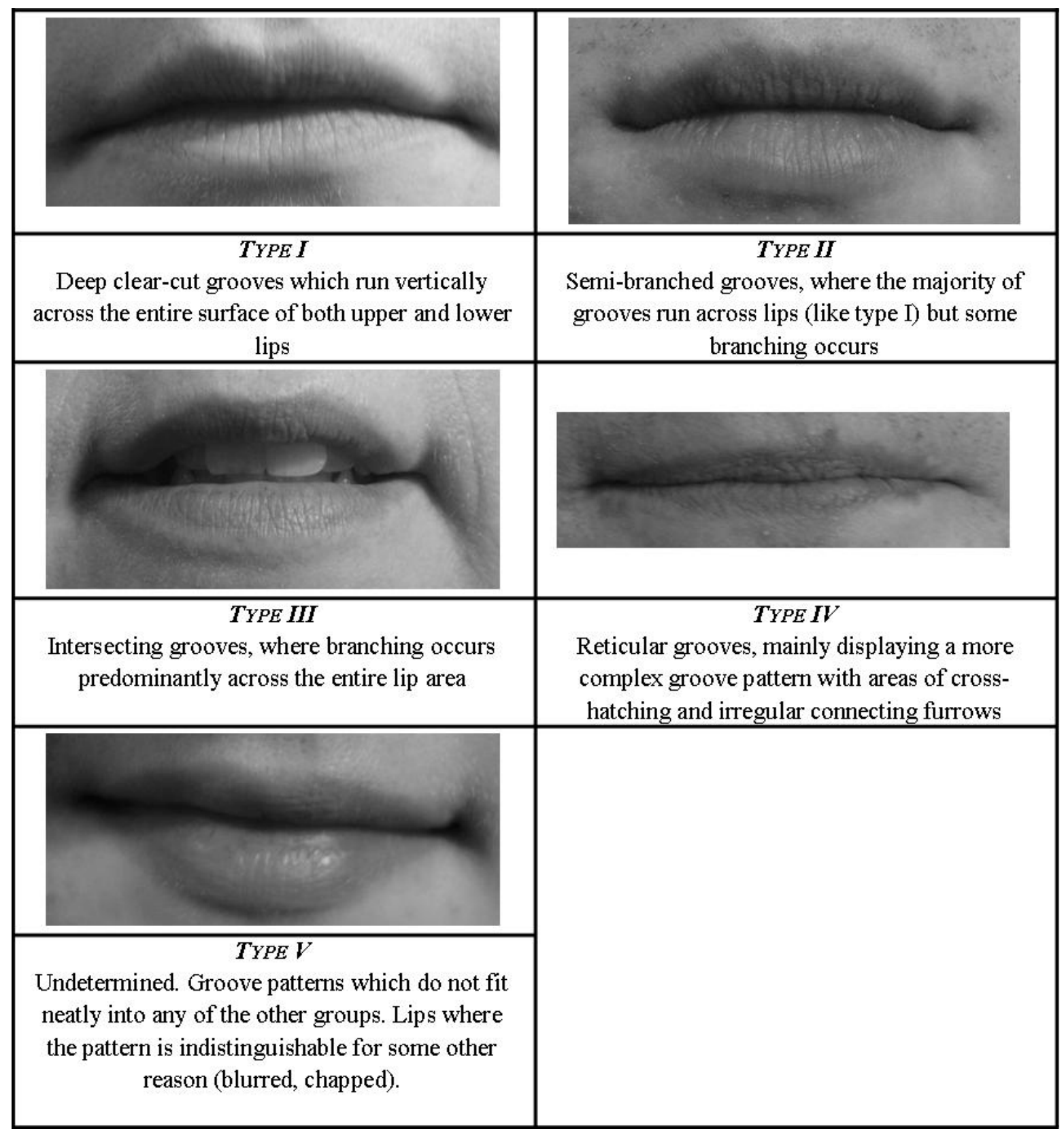

Figure 1: Classification of lip patterns into Type I - Type IV patterns 


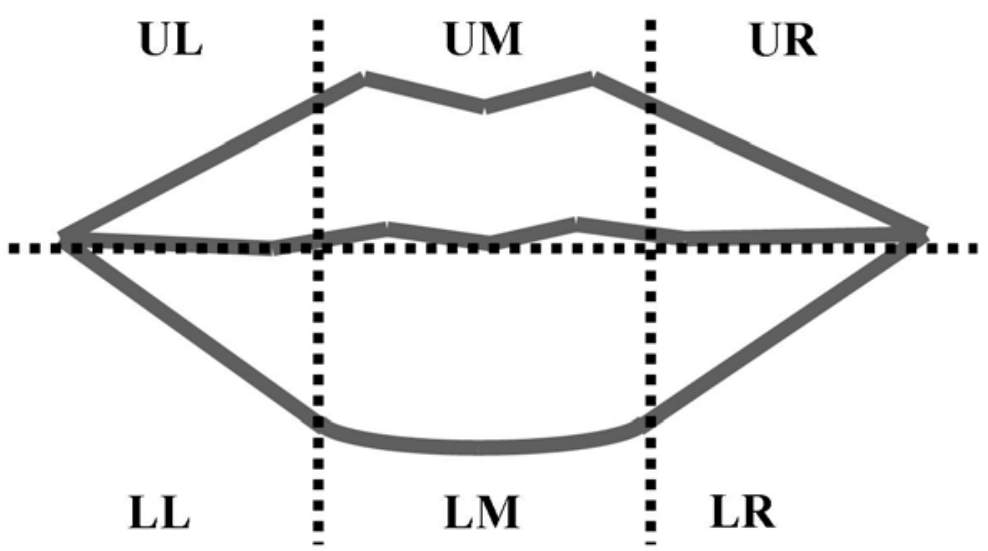

Figure 2: Lip division to aid the determination of pattern classification. The upper and lower middle sections were used to determine the classification group to which the print was allocated. These sections were also utilised when comparing impressions and photographs.

Method for recording

Photographs of volunteers lips were taken using a Fuji Film FinePix® ${ }^{\circledR}$ S2 Pro digital SLR camera with diffused lighting to accentuate the contrast between the furrows and remaining lip background. To create the maximum surface area for comparison purposes, neutral expressions were requested. In order to obtain clear, detailed photographs, participants were asked to sit facing the camera with their heads resting on a chin rest. The full set up is illustrated in figure 3. Several photographs were taken of the lips and a small right-angled photographic scale was attached to the chin rest to give scale and dimensions. The photographs and the impressions were scanned into a computer to allow for cropping and resizing as necessary. 

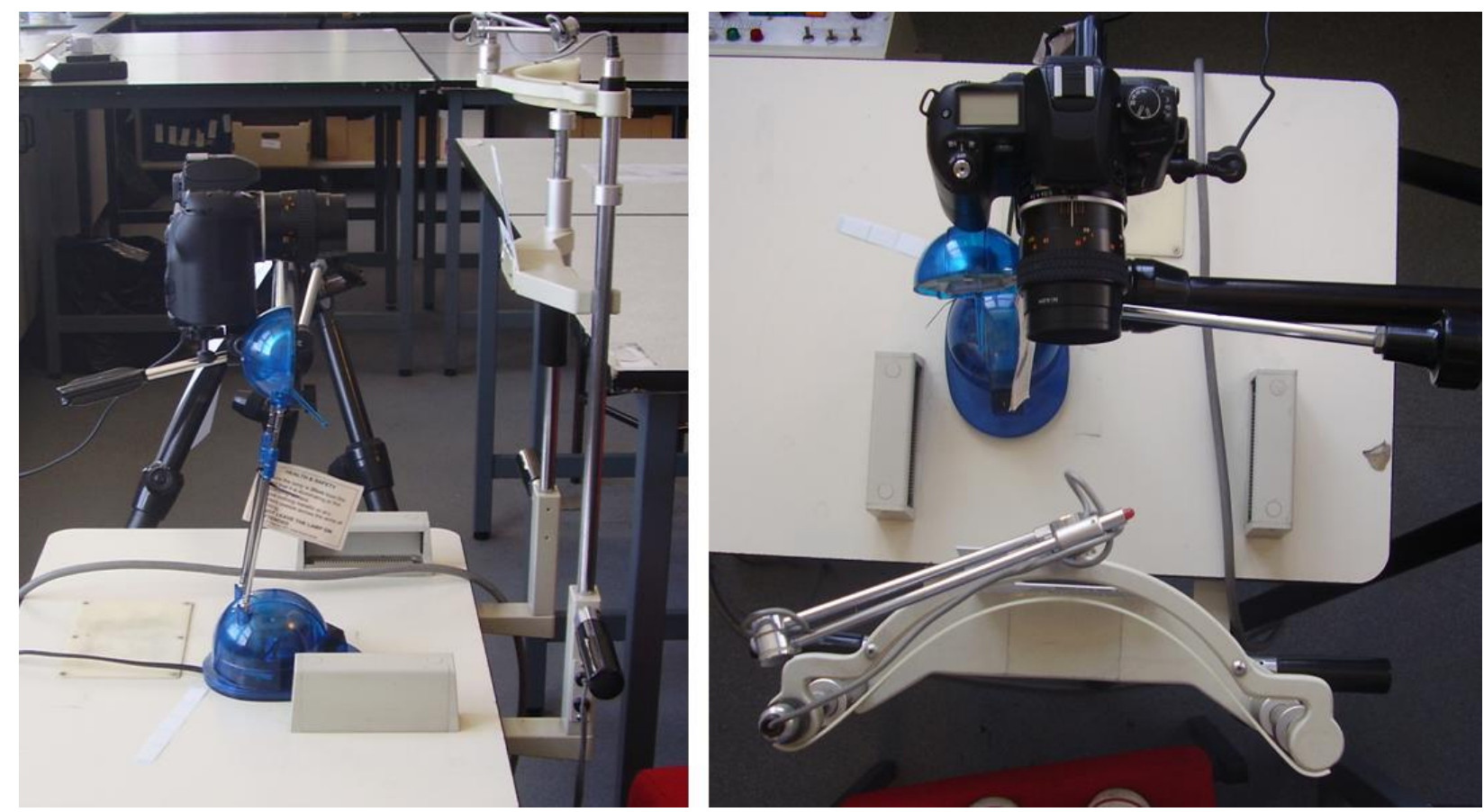

Figure 3: Photographic set up used for obtaining reference pictures.

\section{$\underline{\text { Results }}$}

Classification patterns

The results of the classification of patterns corresponded with previous research ${ }^{18,24}$. In general, the majority of individuals have the same lip print in all of their compartments, very few displayed split patterns when analysing lip print impressions. It was noted however that the four commissural sections (UL, UR, LL, LR) showed trends of differing patterns (where upper and lower middle sections displayed simple furrow designs, commissural sections display more complex furrow systems). The majority of pattern types observed predominantly fell into TYPE I or TYPE II, displaying simple arrangements of furrows and wrinkles (39\% and $25 \%$ of the population respectively). Table 1 illustrates that TYPE III in 22\%, TYPE $I V$ in $8 \%$, and TYPE $V$ only occurred in $6 \%$ of the population. 
Table 1: Frequency of pattern types.

\begin{tabular}{|c|c|c|c|c|c|c|c|}
\hline \multicolumn{2}{|c|}{} & UL & UM & UR & LL & LM & LR \\
\hline \multirow{2}{*}{ TYPE I } & $\mathrm{F}$ & $36 \%$ & $40 \%$ & $36 \%$ & $40 \%$ & $44 \%$ & $40 \%$ \\
& $\mathrm{M}$ & $36 \%$ & $36 \%$ & $36 \%$ & $45 \%$ & $45 \%$ & $45 \%$ \\
\hline \multirow{2}{*}{ TYPE II } & $\mathrm{F}$ & $32 \%$ & $32 \%$ & $32 \%$ & $28 \%$ & $28 \%$ & $28 \%$ \\
& $\mathrm{M}$ & $9 \%$ & $9 \%$ & $9 \%$ & $9 \%$ & $9 \%$ & $9 \%$ \\
\hline \multirow{2}{*}{ TYPE III } & $\mathrm{F}$ & $24 \%$ & $20 \%$ & $24 \%$ & $24 \%$ & $20 \%$ & $24 \%$ \\
& $\mathrm{M}$ & $27 \%$ & $27 \%$ & $27 \%$ & $27 \%$ & $27 \%$ & $27 \%$ \\
\hline \multirow{2}{*}{ TYPE IV } & $\mathrm{F}$ & $4 \%$ & $4 \%$ & $4 \%$ & $4 \%$ & $4 \%$ & $4 \%$ \\
& $\mathrm{M}$ & $18 \%$ & $18 \%$ & $18 \%$ & $9 \%$ & $9 \%$ & $9 \%$ \\
\hline \multirow{2}{*}{ TYPE V } & $\mathrm{F}$ & $4 \%$ & $4 \%$ & $4 \%$ & $4 \%$ & $4 \%$ & $4 \%$ \\
& $\mathrm{M}$ & $9 \%$ & $9 \%$ & $9 \%$ & $9 \%$ & $9 \%$ & $9 \%$ \\
\hline
\end{tabular}

From the sample population no two individuals showed lip patterns which were indistinguishable from each other, although the gross classification groups illustrate that the simple pattern arrangements in TYPE $I$ appeared to be most common within the sample population. Thirty-three percent of the population had pattern Type I across all six quadrants, 17\% had pattern Type II, 19\% pattern Type III, 6\% pattern Type IV and 6\% pattern Type V. Only the remaining $19 \%(\mathrm{n}=7)$ had a mixed pattern. Contrary to recent work by Domiaty et al. ${ }^{20}$, this study found that it was not possible to identify an individual using just the classification system. Therefore, more detailed analysis and comparison of the detailed lip characteristics within each quadrant of the lips was carried out.

\section{Lip print comparison}

To utilise the finer details recovered from the photographs and the scanned lip prints, certain individualising characteristics - similar to minutiae details present in friction ridge analysis were identified and recorded. Figure 4 demonstrates that, similar terminology to fingerprint analysis was used to identify specific identification features, lip pattern imperfections and pattern alignments which were deemed useful for lip print analysis and predominately portray 'transecting lines', 'bifurcations', 'simple openings', and 'islands' 6,7. There was an abundance of the simpler features (e.g. bifurcations, major furrows) which could relate to the mobile function of the lips; continued reoccurrence of such features in different locations allowed the identification of a specific lip impression belonging to an individual. 


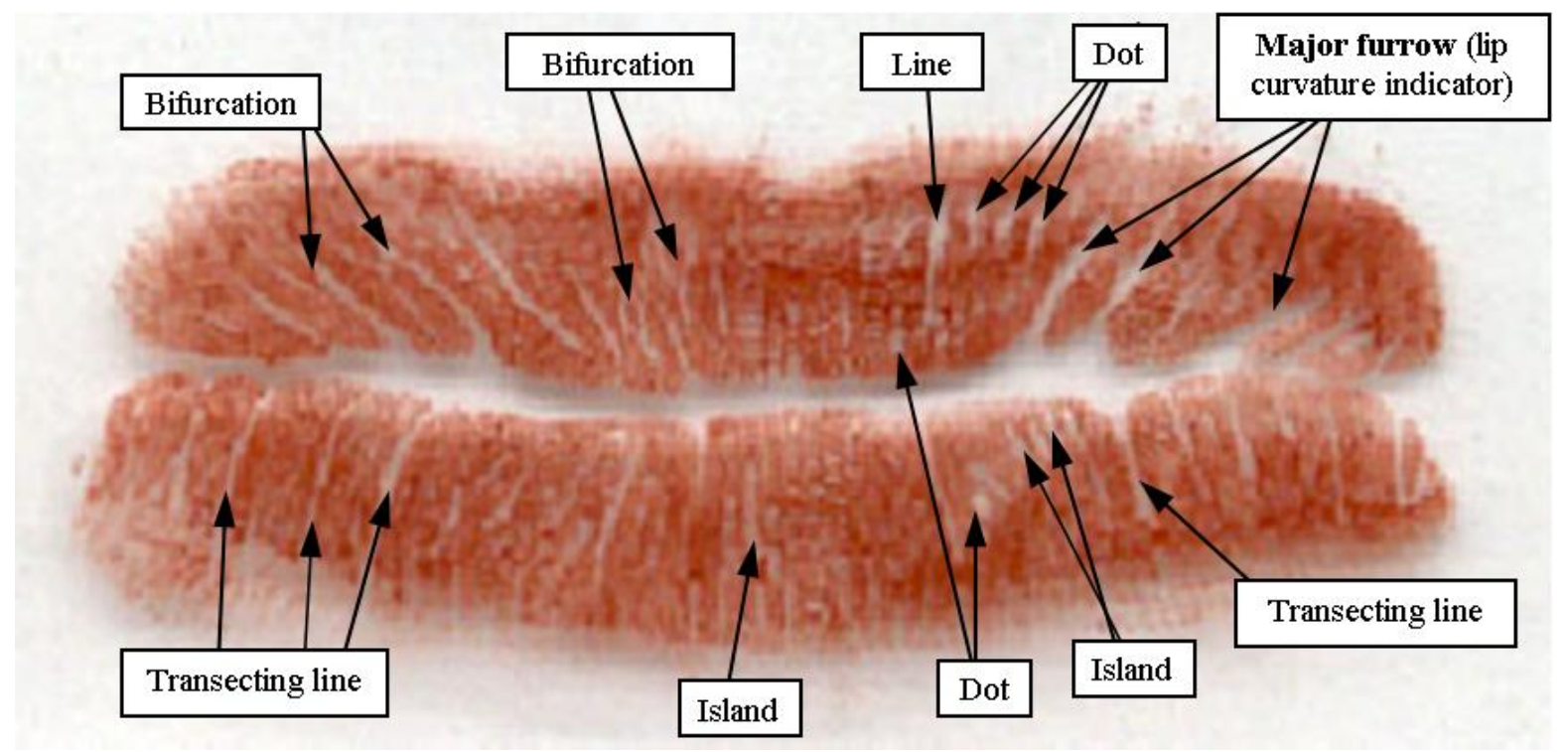

Figure 4: Minutiae annotation (bifurcation, island, etc.) similar to those used for friction ridge analysis were used. Obvious landmarks such as the lip centre, shape and philtrum peaks are utilised for orientation when comparison takes place. These lip pattern imperfections (minutiae) correspond to specific identifying features when compared to another sample.

The combination of these characteristics made it possible to differentiate one impression from any other by comparing lip pattern sections (on both the upper and lower lip) and noting minute points of similarity between the known (reference) impression and the recovered impression. Therefore, although the number of imperfections found on lip patterns was limited, the combination and correlating relationship of details to one another consequently influences and reduces the likelihood of two people have exactly the same distribution of details.

Each photograph or impression was annotated individually and randomly before any comparisons began. To determine the accuracy of the details identified from a lip print, they were compared to the details visible from a photograph of the source lips. An overlay method, whereby the details noted from the lipstick print (kept constant in relation to one another and in size) were imposed onto the photograph and re-adjusted (to a 1:1) scale to determine if any similarities existed between the identified characteristics. Where fingerprint identification utilises ridge counts and anchor points (deltas), these features are not as apparent in lip prints. Figure 5 illustrates where the upper points of the lips at the philtrum 
and the centre of the upper lip line must be used as reference points (marked with a cross in figure 5).
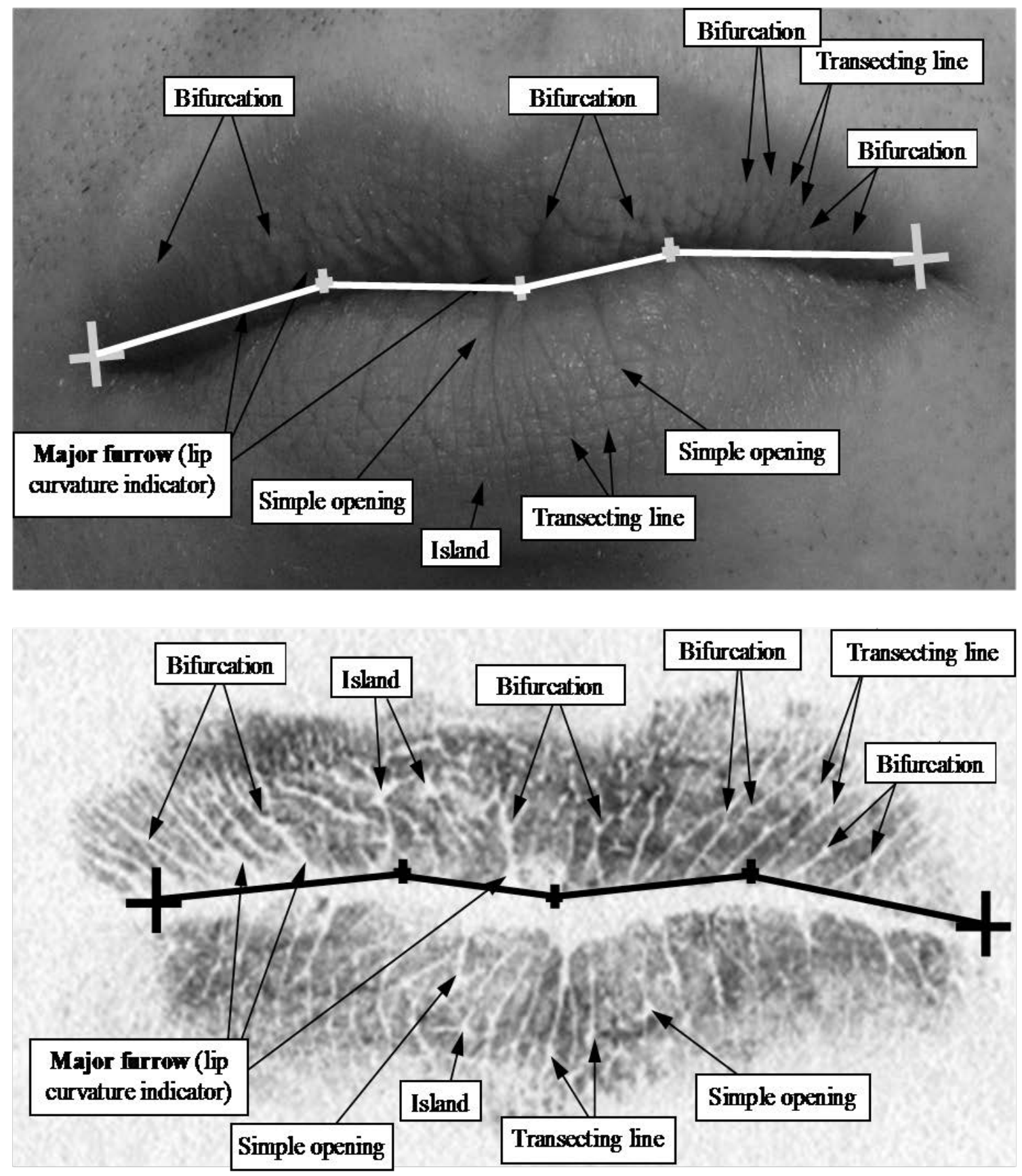

Figure 5: Minutiae detail pattern overlaid onto both lip print and reference photograph.

Comparing the photographed impressions with a selection of unknown print impressions made it possible to determine its origin. The similarities to the photograph provided evidence that lip impressions can be compared to photographs as long as they have not been contorted 
to extreme grimaces or blurred. Figure 6 displays a selection of lip print impressions compared to a source photograph, and determines the number of similarities present between the two (marked by the various coloured dots). The closest match occurs between the photograph and its correct lip impression (D5). All photographs received a new random reference number and comparisons were carried out without the researchers knowing which photograph matched the correct impression.
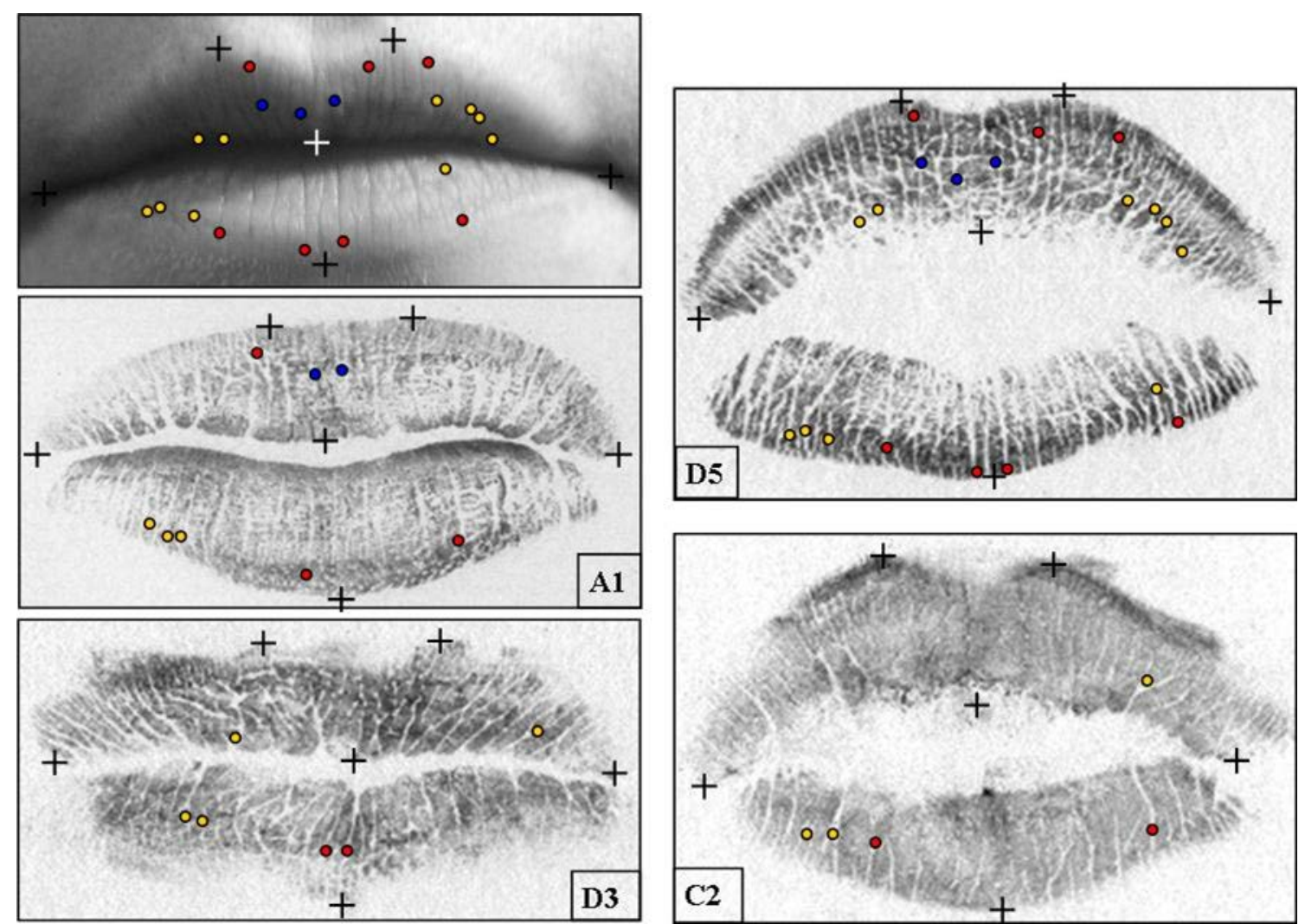

Figure 6: Comparison of several lip impressions with a reference photographs. Pictures have been transformed to grey scale to ease comparison. It is possible to link impression from participant $D 5$ to the original photograph over all other impressions. (Red dots = transecting lines, yellow dots =bifurcations, blue dots = islands/multi-forked bifurcations) 
Table 2: Comparison of a single reference image (photograph) to a number of unknown impressions. The table considers similarity in lip shape, the presence/absence of similarities and differences and the number of points of similarity between image and impression. Grey boxes indicate a positive answer (e.g. similarities could be identified between image and impression) and the stars at A1, B3, B4 identify notable similarities to require further analysis.

\begin{tabular}{|c|c|c|c|c|c|}
\hline $\begin{array}{l}\text { Reference } \\
\text { code }\end{array}$ & $\begin{array}{l}\text { Lip } \\
\text { shape } \\
\text { similar }\end{array}$ & $\begin{array}{l}\text { Detailed } \\
\text { similarities }\end{array}$ & $\begin{array}{l}\text { Notable } \\
\text { dissimilarities }\end{array}$ & $\begin{array}{l}\text { Points of } \\
\text { similarity }\end{array}$ & Notes \\
\hline$A 1 * * *$ & YES & YES & NO & $28+$ & $\begin{array}{l}\text { No visible dissimilarities, a } \\
\text { number of detailed similarities } \\
\text { noted. }\end{array}$ \\
\hline A2 & NO & NO & YES & 11 & Mainly lip shape line similarities. \\
\hline A3 & NO & NO & YES & 4 & Lip shape very dissimilar. \\
\hline A4 & $\mathrm{NO}$ & NO & YES & 10 & Lip shape very dissimilar. \\
\hline A5 & NO & NO & YES & 13 & No similarities in quadrant UM. \\
\hline A6 & YES & NO & NO & 7 & Impression blurred. \\
\hline A7 & NO & NO & NO & 6 & \\
\hline A8 & YES & NO & NO & 4 & $\begin{array}{l}\text { No similarities in quadrant UM or } \\
\text { LM. }\end{array}$ \\
\hline A9 & NO & NO & NO & 10 & Lip shape line similarities. \\
\hline B1 & YES & YES & YES & 14 & \\
\hline $\mathrm{B} 2$ & $\mathrm{NO}$ & - & - & - & Impression not clear. \\
\hline B3 *** & YES & YES & YES & 16 & $\begin{array}{l}\text { Close similarities. Lips appear } \\
\text { fuller. }\end{array}$ \\
\hline B4 *** & YES & YES & YES & 16 & $\begin{array}{l}\text { Close similarities. A number } \\
\text { of detailed dissimilarities. }\end{array}$ \\
\hline B5 & YES & $\mathrm{NO}$ & YES & 12 & \\
\hline B6 & YES & $\mathrm{NO}$ & NO & 4 & \\
\hline B7 & NO & YES & NO & 7 & $\begin{array}{l}\text { One detailed similarity noted in } \\
\text { quadrant UL. }\end{array}$ \\
\hline $\mathrm{C} 1$ & $\mathrm{NO}$ & NO & NO & 7 & Mainly lip shape line similarities. \\
\hline $\mathrm{C} 2$ & YES & YES & YES & 12 & $\begin{array}{l}\text { Close similarities, no similarities } \\
\text { identified in UM. Image blurred. }\end{array}$ \\
\hline $\mathrm{C} 3$ & $\mathrm{NO}$ & $\mathrm{NO}$ & $\mathrm{NO}$ & 11 & Mainly lip shape line similarities. \\
\hline $\mathrm{C} 4$ & NO & YES & YES & 10 & $\begin{array}{l}\text { Close similarities. A number of } \\
\text { detailed dissimilarities. }\end{array}$ \\
\hline $\mathrm{C} 5$ & $\mathrm{NO}$ & $\mathrm{NO}$ & $\mathrm{NO}$ & 7 & \\
\hline C7 & NO & NO & NO & 12 & $\begin{array}{l}\text { Lip shape very different. } \\
\text { Similarities noted lip shape lines. }\end{array}$ \\
\hline $\mathrm{C} 8$ & NO & - & - & - & Impression not clear. \\
\hline C9 & $\mathrm{NO}$ & $\mathrm{NO}$ & NO & 12 & No similarities in top quadrants. \\
\hline D1 & YES & YES & YES & 14 & $\begin{array}{l}\text { Some similarities. A number of } \\
\text { detailed dissimilarities noted. }\end{array}$ \\
\hline $\mathrm{D} 2$ & YES & YES & YES & 15 & $\begin{array}{l}\text { Some similarities. A number of } \\
\text { detailed dissimilarities noted }\end{array}$ \\
\hline D3 & NO & NO & NO & 5 & No similarities in top quadrants. \\
\hline D4 & NO & NO & NO & 5 & No similarities in top quadrants. \\
\hline D5 & YES & YES & YES & 10 & $\begin{array}{l}\text { Close similarities. A number of } \\
\text { detailed dissimilarities. }\end{array}$ \\
\hline D6 & $\mathrm{NO}$ & $\mathrm{NO}$ & NO & 10 & No similarities in top quadrants. \\
\hline D7 & $\mathrm{NO}$ & $\mathrm{NO}$ & $\mathrm{NO}$ & 6 & No similarities in lower quadrants. \\
\hline
\end{tabular}




\begin{tabular}{|l|c|c|c|c|l|}
\hline D8 & NO & NO & NO & 4 & \\
\hline D9 & YES & NO & NO & 6 & \\
\hline E1 & NO & NO & NO & 7 & \\
\hline E2 & NO & - & - & - & Impression not clear. \\
\hline E3 & NO & NO & YES & 6 & \\
\hline
\end{tabular}

The photograph was compared manually with each of the 36 impressions taken. In order to minimise the background effects from the colours, all photographs and scans of lip impressions were altered to black and white images. This was done as human eyes perceive colours differently between individuals, and are generally less sensitive to the colour red ${ }^{25}$. Photographs and impressions were compared, working from the centre out of both the upper and lower lip and any details of any similarities or differences were noted. Impressions which were made by the lips photographed always showed a higher number of points of similarity. Impression which accurately matched the photographs displayed 20 or more matching characteristics. Complexities of the marks (e.g. lip line furrow, transecting line, bifurcation) were taken into consideration as well as the location of the match (i.e. quadrant number). Similarities in the middle quadrants were considered carefully, as these sections contained the greatest surface area. The majority of the intricate furrow details were found in the middle quadrants.

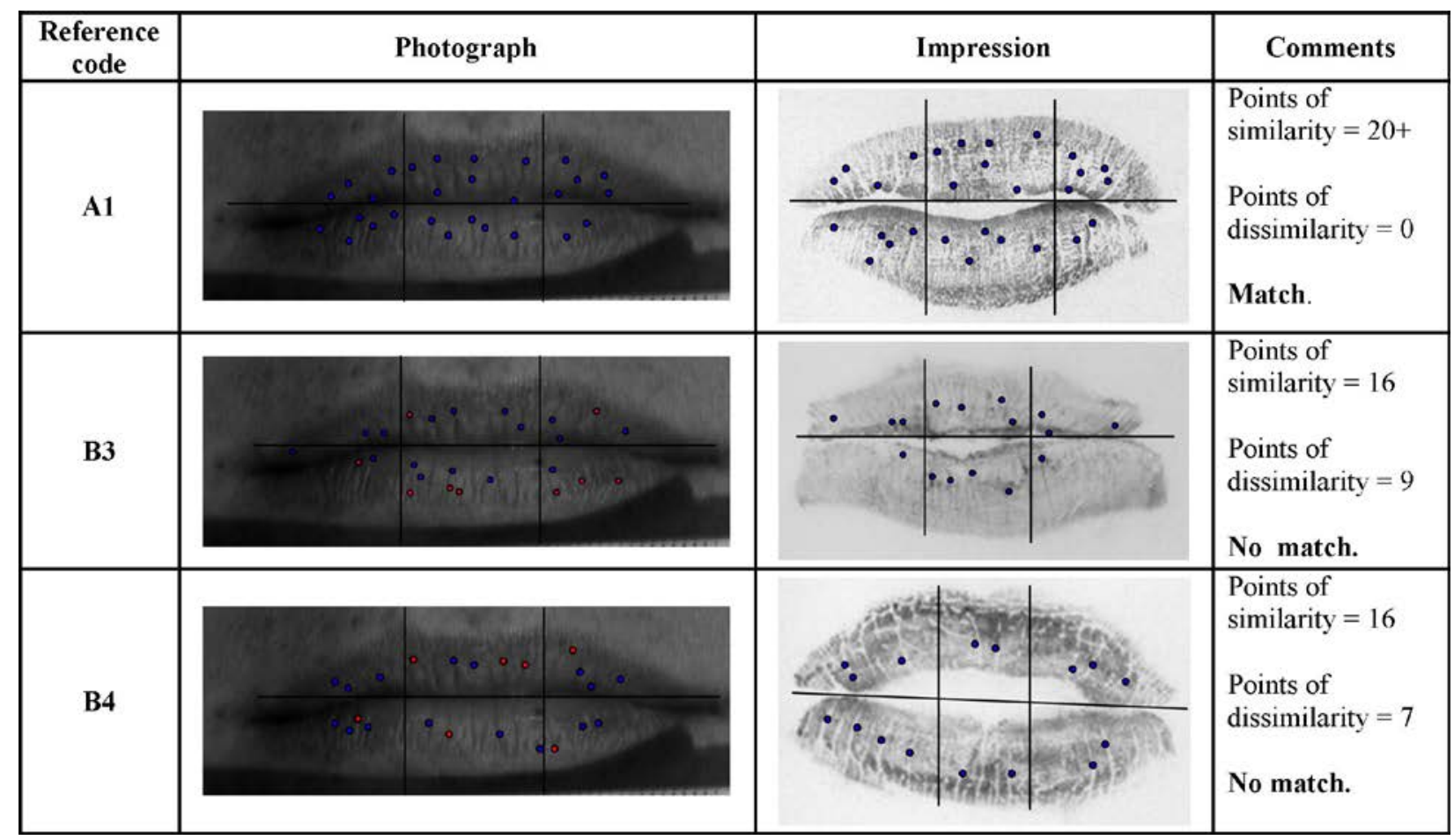

Figure 7: Comparison of reference photograph to several closely matching impressions. Any similarities and differences have been noted (blue dots = similarities, red dots $=$ differences). 
Table 2 illustrates the comparison between one image and the impressions taken. As shown, comparisons considered whether lip shapes were similar, whether a number of detailed similarities could be identified (e.g. bifurcations, islands) and in which quadrants these occurred, whether any dissimilarities could be identified, and the number of points of comparison. Impressions which were found to demonstrate a number of similarities were then analysed further to see if this could be narrowed down to a single impression. Table 2 illustrates that impressions A1, B3 and B4 identified a number of close similarities and required further comparison. Figure 7 illustrates the comparison between image 1 and each of the three impressions. Notable dissimilarities are highlighted, and the results correctly identify A1 to be a match.

\section{Gender differences of lip prints}

A sample population of 25 females and 11 was utilised in this study. The gender dominance of female participants involved causes some concern for bias contamination and results must be interpreted independently to the female population as a whole as well as compared to the male population. Considered with independent gender variables, the data showed that the TYPE I pattern appeared in $36.3 \%$ of the male population and $40 \%$ in the female population. TYPE II proved dominant in the female population (32\%) and TYPES III, IV \& V were greater in males (27.3\%, $18.2 \%$ and $9.1 \%$ respectively).

The data displays a relatively even distribution of patterns in the male population, with classification TYPE II (branched) and TYPE V (undetermined) showing the lowest population frequency (9.1\%). In the female population pattern TYPE IV (reticular grooves) and TYPE $V$ (undetermined pattern) showed the lowest frequency. Statistical differences between pattern types and males and females were not observed (Mann-Whitney, $\mathrm{p}>0.05$.). The distribution of pattern type between genders is the same.

\section{Discussion \& Conclusion}

Lip furrow details were evaluated using a pattern comparison technique similar to friction ridge skin analysis between reference and unknown impressions and as such, the comparison is considered to be subjective. The process of comparing and connecting prints (unknown to 
reference) proved difficult and time consuming due to a lack of a uniformly recurrent reference point from which to orientate the analysis. Utilising an overlap technique, the results showed that lip prints could be used to identify an individual by comparing impressions and photographs. Lip line shape, as well as lip furrow details were annotated on the impression and correlated with the features of the photographs taken from the same individual. In agreement with Caldas et al. ${ }^{6}$ the ability to associate unknown prints however, proved a much more difficult and time consuming task as it was not always possible to determine the same clearly distinct features or to guarantee the same features were annotated due to the lack of points of constant reference from which to analyse the prints.

However, this research has identified that it is possible to match an impression with a reference photograph via a means of deduction. Firstly, comparisons of lip patterns using the classification system can reduce the number of potential impressions for comparison. Secondly, detailed analysis of lip shape and minute details can determine a number of close matches. Thirdly, analysis of any dissimilarity between impressions and photographs were able to identify a possible source. This research was able to accurately link an impression collected to the prints in a photograph and vice versa. The comparison of photograph to unknown impressions was also able to determine a single, or one of two possible sources in over $90 \%$ of cases.

Although the number of imperfections found on lip patterns was limited, the combination and correlation of details to one another consequently influences and reduces the likelihood of two people have exactly the same distribution of details. The current research indicated that the composition and relative distribution of the wrinkles and furrows visible on the coloured part of the human lips were distinguishable between individuals, and similar methods as used in fingerprint comparison to establish a match could be applied. As Champod et al. ${ }^{26}$ reasoned, lip furrows can be displayed as a "stratified surface trace" where the individual properties of the print make it possible to identify a human being. This research supports this statement and is in agreement with previous findings: lip prints contain a number of different patterns and details which allow individuals to be identified ${ }^{1,2,14,20,22}$.

The main limitations of lip print identification relate to the lack of statistical studies available to assess the variability of lip prints using a large cross-section of the population, and the mobility of the lips which can produce different prints from the same individual. This research found that different impressions could be recorded from the same lips due to variation in pressure applied during the collection process, direction of force as well as 
method and substance used to take and collect impression. The methodology implemented as part of this study found that good, clear impressions could be obtained from pressing the lips down using enough pressure to hold the paper between the lips. Taking multiple impressions without reloading the lips with lipstick also provided a choice of impressions from which the clearest image could be used for comparison. In agreement with Ball ${ }^{7}$, this research also identified paper to be the best substrate for collecting detailed impressions.

The study has carried out preliminary work for establishing an alternate means of identification through the detailed analysis and comparison of minute characteristics which can be visualised and recorded from the lips of individuals. Lip print analysis can utilise methodologies from fingerprint comparisons where similarities between two prints are identified and expert analysis determines whether the source of the impression can be linked to an individual. The use of lip prints as an alternative means of identification provides the possibility for the creation of a database containing ante-mortem and known sample records, which can then be used to compare to post-mortem and crime scene impressions for personal identification ${ }^{5}$.

Furthermore, external or environmental effects such as smoking, drug dependency and stress levels may also produce notable details on a lip impression which may be indicative for intelligence purposes. Factors such as diet, fitness and general health are all known to affect lip structure; however their consequences on lip pattern detail needs to be investigated further. Other environmental effects (e.g. frostbite, humidity, sea spray) or individuals regularly exposed to the elements (e.g. outdoor labourer, traffic warden, gardener) should be investigated to determine if influence of pattern details and lip texture is observed. This would be in line with findings from Domiaty et $a l^{20}$ who identified the hot climate in Saudi Arabia cause lips to dry subsequently affecting the impressions taken.

\section{Acknowledgements}

The authors would like to thank Dr. T.J.U. Thompson for critical reading of the manuscript as well as the reviewers for their helpful suggestions.

\section{References}

1. Suzuki K, Tsuchihashi Y, Personal identification by means of lip prints. J of Forensic Med. 1970; 17: 52-57. 
2. $\quad$ Suzuki K, Tsuchihashi Y, Two Criminal cases on lip prints. Act Crim Japon. 1975; 41(2): 61-64.

3. Kaur R, Garg R, Personal identification from lip prints. Forensic Sci Int 2007; 169 S: S47-49.

4. Suzuki K, Tsuchihashi Y, New attempt of personal identification by means of lip print. J Indian Dent Assoc. 1970; 42(1): 8-9.

5. Utsuno $\mathrm{H}$, Kanoh $\mathrm{T}$, Tadokoro $\mathrm{O}$, Inoue $\mathrm{K}$, Preliminary study of post mortem identification using lip prints. Forensic Sci Int. 2005; 149(2-3): 129-132.

6. Caldas IM, Magalhães T, Afonso A, Establishing identity using cheiloscopy and palatoscopy. Forensic Sci Int. 2007; 165: 1-9.

7. Ball J, The current status of lip prints and their use for identification. J Forensic Odontostomatol. 2002; 20(2): 43-46.

8. Ho TP, Azar K, Weinstein S, Bowley WW, Physical properties of human lips: experimental and theoretical analysis. J Biomech. 1982; 15(11): 859-866.

9. Fogel MR, Stranc MF, Lip function: a study of normal lip parameters. Br J Plast Surg. 1984; 37: 542-549.

10. Bisson M, Grobbelaar A, The aesthetic properties of lips: a comparison of models and non-models. Angle Orthodontist. 2004; 74(2): 162-166.

11. Sivapathasundharam B, Prakash PA, Sivakumar G, Lip prints (Cheiloscopy). Indian J Dent Res. 2001; 12(4): 234-237.

12. Navarro E, Castelló A, López-Alfaro J, Verdú F, More about the developing of invisible lipstick-contaminated lipmarks on human skin: The usefulness of fluorescent dyes. J Forensic Leg Med. 2007; 14(6): 340-342.

13. Hirth L, Gottsche H, Goedde HW, Lippenfurchen: Variabilität und Genetik. Humangenetik. 1975; 30: 47-62.

14. Tsuchihashi Y, Studies on personal identification by means of lip prints. Forensic Sci. 1974; 3(3): 233-248.

15. Kobayashi H, Tagami H, Functional properties of the surface of the vermilion border of the lips are distinct from those of the facial skin. Brit J Dermatol. 2004; 150(3): 563-567.

16. Lévêque JL, Goubanova E, Influence of Age on the Lips and Perioral Skin. Dermatology. 2004; 208: 307-313.

17. Kasprzak J, Possibilities of Cheiloscopy. Forensic Sci Int. 1990; 46: 145-151.

18. Afchard-Bayat M, Klassifizirungsystem für Lippenabdrücke. Kriminalistik. 1979; 3(1).

19. Alvarez-Seguí M, Miquel-Fecht M, Castelló-Ponce A, Verdú PFA, Persistent lipstick and their lip prints: new hidden evidence at the crime scene. For Sci Int. 2000; 112: 41-47.

20. Domiaty MAE, Al-gaidi SA, Elayat AA, Safwat MDE, Galal SA, Morphological patterns of lip prints in Saudi Arabia at Almadinah Almonawarah province. Forensic Sci Int. 2010; 200(1-3): 179.e1-179.e9.

21. Ehara Y, Marumo Y, Identification of lipstick smears by fluorescence observation and purge-and-trap gas chromatography (Value of human lip lines and nail striations in identification). Forensic Sci Int. 1998; 96: 1-10.

22. Williams TR, Lip Prints: Another Means of Identification. J Forensic Ident. 1991; 41(3): 190-194.

23. Santos M, Queiloscopy a supplementary stomatological means of identification. Int Microform J Leg Med. 1967; 2: 66.

24. Bisdson M, Grobbelaar A, The esthetic properties of lips: a comparison of models and nonmodels. Angle Orthod. 2004; 74: 162-166. 
25. HOSDB, Fingerprint and Footwear Forensics Newsletter. 2009.

26. Champod C, Lennard C, Margot P, Stoilovic M, Fingerprints \& Other Ridge Skin Impressions. International Forensic Science \& Investigation Series. 2004: CRC Press. 